\title{
Professores de inglês da rede pública paranaense e o ensino da pronúncia
}

\author{
Andressa B. Albini ${ }^{1}$ \\ Denise Kluge $^{2}$
}

\section{Resumo}

Este artigo objetiva discutir algumas questões relacionadas à importância da pronúncia para professores brasileiros de inglês, tais como: $\mathrm{O}$ que os professores pensam sobre este assunto? Os professores de inglês da rede pública deveriam ter conhecimento de Fonética e Fonologia para ensinar inglês? A falta deste conhecimento pode influenciar o aprendizado dos alunos? Os professores tiveram aulas de pronúncia ao longo de sua formação? Os professores têm dificuldade de pronúncia em inglês? Quais? Estes professores consideram sua própria pronúncia importante para seus alunos? Para discutir essas e outras perguntas, um questionário foi desenvolvido e aplicado para um grupo de professores de inglês formados em Letras que trabalham em escolas da rede pública da região metropolitana de Curitiba. Para fins comparativos, o mesmo questionário também foi aplicado a um grupo de professores de inglês de cursos ou escolas particulares e professores universitários. Os resultados apontam as dificuldades, os desafios e a preocupação destes professores de inglês em relação a sua própria pronúncia e ao ensino desta na sala de aula.

Palavras-chave: Ensino de pronúncia do inglês. Formação de professores. Pronúncia do inglês.

\begin{abstract}
This article aims at discussing some relevant issues related to the importance of pronunciation in the education of Brazilian English teachers through some questions such as: What do teachers think about it? Do they teach pronunciation to their students? Should teachers know English Phonology in order to teach English? Does this lack of information influence student's learning? Did teachers have pronunciation classes throughout their education? Do teachers have difficulties in English pronunciation? Which ones? Do they consider their own pronunciation important to their students? In order to discuss these topics, one questionnaire was applied to a group of Brazilian English teachers working at public schools in Paraná. As reference for comparison, the same questionnaire was applied to a group of English teacher working at private schools and at university. In general, the results reveal their difficulties, their concern about their own pronunciation as well as their challenges in teaching it.
\end{abstract}

Keywords: Pronunciation teaching. English teacher pronunciation. English teacher education.

${ }^{1}$ Mestre. Doutoranda UFPR. E-mail: andbraw@yahoo.com

${ }^{2}$ Doutorado em Letras (Inglês e Literatura Correspondente) pela Universidade Federal de Santa Catarina, Brasil(2009). Professor Adjunto da Universidade Federal do Paraná- Campus Litoral , Brasil. E-mail: deniseckluge@gmail.com 


\section{Introdução}

De maneira geral, o ensino de pronúncia nas escolas públicas brasileiras tem sido bastante negligenciado (PISKE, 2007; MOREIRA, 2001). Muitos professores não gostam e/ou não estudam o assunto por não terem tido a formação necessária ou por não se sentirem seguros, preferindo omitir esta parte do ensino. De acordo com Koerich (2002), a maioria dos professores de inglês brasileiros não recebeu treinamento em Fonética e Fonologia nas últimas décadas. Comparando-se a quantidade de exercícios dedicados à pronúncia e o tempo dedicado à prática de outras habilidades nos livros didáticos ou na sala de aula de forma geral, percebe-se que o ensino de pronúncia é muitas vezes negligenciado. Estas afirmações nos levam a algumas reflexões, tais como: Os professores de inglês da rede pública estudaram Fonética e Fonologia na sua formação? Os professores têm dificuldade em aprender ou ensinar pronúncia? Quais são elas? Eles efetivamente ensinam pronúncia na sala de aula? Estes professores acham que sua pronúncia pode influenciar a de seus alunos? Até que ponto o input fornecido pelos professores influencia a pronúncia dos alunos de língua estrangeira? Quais são as dificuldades de pronúncia dos alunos que os professores percebem com mais frequência? Como lidam com elas?

Segundo Watkins, Brawerman-Albini e Bertochi (2010), muitos alunos e professores de inglês comentam que a pronúncia é constantemente deixada de lado, sem treinamento específico. Ainda, professores nativos são raros e uma causa comum da pronúncia incorreta dos alunos é simplesmente um input incorreto e a falta de correção. Assim, a instrução e a prática de pronúncia de forma mais eficiente certamente beneficiaria muitos brasileiros, tornando-os mais facilmente compreendidos em um mundo que cada vez mais utiliza a língua inglesa para a comunicação oral. Ainda, Holden \& Rogers (2002) destacam o fato de que os alunos tendem a imitar seus professores, tomando-os como exemplo. Desta forma, quando os professores apresentam dificuldades com a pronúncia e não ensinam explicitamente a forma correta, seus alunos irão provavelmente incorporar tais dificuldades.

Delatorre (2007) argumenta que a falta de conhecimento de alguns professores faz com que eles tenham dificuldades em identificar erros na pronúncia de seus alunos e em ajudá-los a resolvê-los. A autora mostra, ainda, que os professores possuem dificuldades com a fonologia da língua inglesa possivelmente porque este é um campo considerado muito difícil por professores e alunos de Letras. 
Outro aspecto muito discutido atualmente é que tipo de pronúncia ensinar aos futuros professores e alunos de inglês: uma pronúncia inteligível ou uma pronúncia semelhante ao do falante nativo? De um lado, Kenworthy (1987) (apud CRUZ, 2007) sugere que, apesar de que a pronúncia inteligível deva ser o alvo a ser atingido pela maioria dos aprendizes de inglês, aqueles que desejam ser professores devem ter uma pronúncia próxima à do falante nativo de inglês. Por outro lado, Jenkins (2000) não concorda com a ideia da pronúncia do nativo como alvo, tanto para aprendizes quanto para professores, argumentando que o número de falantes não-nativos de inglês excede o de nativos e que o objetivo do ensino deve ser a inteligibilidade. Baseado nestas colocações, Cruz argumenta que os professores devem, antes de tudo, conhecer os anseios de seus alunos:

Temos o receio de que, talvez, ao propormos um alvo de pronúncia que não seja aquele que os alunos almejam, eles possam se sentir desmotivados a praticar e estudar pronúncia, uma vez que os seus objetivos de alcançar a pronúncia do nativo poderão ser abandonados. (2007, p. 370).

Moreira (2001) investigou como os professores de inglês ensinam pronúncia nas escolas públicas na região metropolitana de Florianópolis. Os resultados mostraram que a maioria dos professores de inglês, que são não-nativos, não ensina pronúncia porque não se sente confiante ou apto suficientemente para isso. A maioria dos professores dessa pesquisa revelou que não receberam instrução em fonética e/ou fonologia do inglês durante a sua formação na graduação. Esta situação é muito intrigante, já que instrução em pronúncia é bastante eficiente e necessária principalmente nos níveis iniciais de aprendizagem da L2 (BAPTISTA, 2000).

Brawerman (2006) realizou uma pesquisa para analisar a produção do acento por estudantes brasileiros de inglês em palavras sufixadas. Os resultados mostraram que o padrão pré-proparoxítono é bastante problemático para brasileiros, que assinalam este acento de forma constantemente incorreta. O grande problema é que palavras do tipo pré-proparoxítonas são extremamente raras no português brasileiro (PB) e deve haver uma restrição muito forte bloqueando este tipo de acentuação pelos falantes de PB. Esta dificuldade seria agravada pelo fato de que os estudantes brasileiros dificilmente ouvem essas palavras acentuadas de forma correta, já que muitos dos seus professores são brasileiros que também possuem esta forte restrição ao acento pré-proparoxítono. A falta de conhecimento dos professores também gera falta de correção durante as aulas, não dando oportunidade aos alunos de tentar consertar seus erros. Com a soma de input incorreto e falta de correção, dificilmente o output será correto. 
A partir dos resultados deste trabalho, Brawerman-Albini (2009) fez uma pesquisa com alunos de Letras para verificar se eles também possuem esta dificuldade com o acento préproparoxítono. Como eles serão futuros professores de inglês, poderia se checar que tipo de input eles passarão aos seus alunos. Novamente, demonstrou-se a grande dificuldade na produção do padrão pré-proparoxítono se comparado aos padrões comuns no PB (paroxítono e proparoxítono). Pode-se acreditar que esta restrição da língua materna é tão forte que só pode ser superada por falantes brasileiros, sejam alunos ou professores, a partir de uma extensa prática. Entretanto, como já foi mencionado, essa prática em atividades de pronúncia parece ser bastante incomum nas salas de aula.

A partir das reflexões do trabalho de Moreira (2001) com professores de inglês, e de Brawerman (2006) e Brawerman-Albini (2009) com estudantes brasileiros de inglês e futuros professores estudantes de Letras, respectivamente, Brawerman-Albini e Kluge (2010) conduziram uma pesquisa preliminar a fim de investigar o papel do ensino de pronúncia na formação e na prática em sala de aula para professores e futuros professores de inglês. Os participantes foram compostos por dois grupos: um, formado por 11 professores de inglês formados em Letras que trabalham ou já trabalharam em escolas da rede pública do Paraná; e outro formado por 15 futuros professores, estudantes de Letras (Inglês ou Português/Inglês) da Universidade Federal do Paraná. Os resultados mostraram que, de forma geral, a maioria dos professores e alunos de Letras pesquisados considera a pronúncia importante em sua formação, apesar de não exercer um papel essencial. Ambos os grupos também demonstraram uma percepção clara da influência de sua pronúncia na de seus alunos e do quanto é importante que eles tenham uma pronúncia correta e conhecimentos teóricos que os ajudem na identificação dos problemas de seus alunos/futuros alunos. Os resultados também revelaram que tanto os professores quanto os estudantes de Letras demonstraram interesse em aumentar seus conhecimentos de fonologia e melhorar suas pronúncias.

A partir dos estudos revisados acima e baseado nos resultados preliminares de Brawerman-Albini e Kluge (2010), esta pesquisa objetiva investigar e discutir mais amplamente a pronúncia do inglês em relação ao seu ensino, dificuldades e desafios para um grupo de professores de inglês da rede pública paranaense. Além de analisar os resultados dos questionários aplicados a este grupo, serão aplicados também questionários para professores de escolas ou cursos particulares de inglês e para professores universitários para proporcionar uma comparação com os professores de escolas públicas, que são o foco deste artigo. 


\section{Método}

Os participantes foram compostos por dois grupos. O primeiro grupo foi composto por 19 professores de inglês formados em Letras que trabalham ou já trabalharam em escolas da rede pública do Paraná. O tempo de docência destes professores varia de 1 a 26 anos, com média de aproximadamente 11 anos de experiência em sala de aula. Para fins comparativos, o segundo grupo foi composto por sete professores de inglês que trabalham em escolas ou cursos particulares e por quatro professoras que lecionam em universidades federais. O tempo de docência desses professores neste tipo de escola/universidade variou de 1 a 15 anos, com média de três anos e meio.

O questionário aplicado aos professores de inglês dos dois grupos (Anexo) foi o mesmo aplicado por Brawerman-Albini e Kluge (2010). O questionário contém 12 perguntas sobre a importância da pronúncia na aprendizagem da língua, a ênfase dada à pronúncia na sua formação, o que eles pensam sobre o assunto e como abordam a pronúncia em suas aulas. Os questionários foram respondidos individualmente e em português para garantir que os participantes pudessem expressar melhor suas opiniões.

Para a análise preliminar dos questionários, optou-se por analisar somente as perguntas relevantes ao objetivo específico deste artigo. Para tanto, em relação à importância da pronúncia e do ensino desta, foram analisadas as perguntas 2, 8 e 11. Em relação ao papel da pronúncia na formação destes professores de inglês, foram analisadas as perguntas 4, 5, 6 e 12. As respostas das perguntas relacionadas acima serão apresentadas e discutidas na seção seguinte.

\section{Resultados do questionário aplicado ao grupo de professores da rede pública}

Conforme mencionado anteriormente, foram analisadas as perguntas 2, 4, 5, 6, 8, 11 e 12 do questionário. Em relação à importância da pronúncia no ensino do inglês (perguntas 2, 8 e 11), de um modo geral, parece que a maioria dos professores de inglês pesquisados considera a pronúncia importante, mas não prioritária ou principal no ensino da língua inglesa. Analisando a pergunta 2 do questionário, que pede para que os professores numerem a importância das habilidades de uma escala de 1 a 6, sendo 1 a mais importante e 6 a menos importante, percebe-se que a posição ocupada pela pronúncia em relação a outras habilidades 
não é prioritária. Oito dos 19 professores pesquisados marcaram a pronúncia como quinta ou sexta colocada; três consideraram como quarta e oito professores numeraram a pronúncia como segunda ou terceira colocada. Apesar das opiniões estarem bastante divididas, percebese que muitos professores não priorizam a pronúncia em relação às outras habilidades e nenhum a considera a mais importante. Percebe-se também que para muitos dos professores que marcaram a pronúncia como terceira colocada, ela vem após fala e compreensão oral, mostrando uma grande tendência à prioridade da comunicação.

Ao responder a questão 8, que pergunta aos professores sobre a importância do ensino da pronúncia, todos consideraram o ensino de pronúncia importante. De um modo geral, os professores consideram o ensino da pronúncia muito importante, pois proporciona ao aluno “uma boa aprendizagem de fala” e “oportuniza ao aluno uma melhor conversação”. Também conscientiza o aluno de que "uma pronúncia mais correta traz uma melhor compreensão", fazendo com que “o contexto não seja prejudicado”. Uma professora considera que “o ensino de pronúncia é uma forma de mostrar respeito pela língua estrangeira quando a falamos”. Um dos professores ressaltou que acredita que o ensino da pronúncia é importante, mas somente após o ensino da gramática.

Em relação à pergunta 11, que questiona como os professores destacam a importância de sua pronúncia na aprendizagem de seus alunos, todos os participantes a consideram de extrema importância, pois “os alunos irão se basear na pronúncia do professor”, que "serve de modelo para os alunos”. Os professores teriam uma “enorme responsabilidade”, pois devem “pronunciar o mais corretamente possível”. Segundo uma professora, “se a minha pronúncia não for adequada, com certeza os alunos aprenderão errado”.

As perguntas 4, 5, 6 e 12 investigaram o papel da pronúncia na formação dos professores desta pesquisa. A pergunta 4 questionava se os professores cursaram alguma matéria específica de pronúncia ou fonologia da língua inglesa durante a graduação. Apenas dois dos participantes responderam afirmativamente. A maioria dos participantes respondeu que nunca cursou matéria que abordasse tal tema, pois esse tipo de disciplina não era ofertado, mas que gostaria de ter cursado por considerar essa disciplina muito importante.

A pergunta 5 questionava se os professores consideram o ensino de pronúncia que tiveram durante a sua formação suficiente. Apenas dois professores o consideram suficiente e 17 professores responderam que consideram o ensino de pronúncia insuficiente durante sua formação. A maioria relatou que, infelizmente, teve pouco enfoque deste assunto durante a graduação. Uma professora falou que na época de sua graduação, “a ênfase maior era em 
gramática” e outra disse que "pautava-se muito em transcrição fonética”. Segundo ela, hoje o ensino pode ser mais diversificado, “tornando a matéria mais agradável e inteligível”.

A questão 6, que pergunta se os professores possuem dificuldade com a pronúncia da língua inglesa, obteve seis respostas negativas e 13 respostas positivas. As maiores dificuldades relatadas pelos professores que responderam afirmativamente foram dificuldade com a pronúncia em geral, dificuldade em compreensão de sotaques diversos, problemas com a compreensão oral de forma geral e dificuldade com a acentuação das palavras e com sons específicos como o "th" e vogais.

Todas as respostas da questão 12, que perguntava se os professores acreditavam que o conhecimento de noções teóricas da fonologia da língua inglesa era importante na sua formação de professor, foram afirmativas. De maneira geral, os participantes acreditam que o professor tem que ter o conhecimento teórico profundo da língua para melhor ensinar o aluno, pois “teoria e prática se complementam”. Dois dos professores também destacaram que o conhecimento teórico é “a base da boa pronúncia”. Uma professora disse que o embasamento teórico a deixa mais segura em suas aulas e essa segurança é repassada a seus alunos. Outra mencionou que "por conta do inglês estar mais em evidência hoje em dia, é importante estar mais preparado não só para falar mais corretamente, mas também para entender melhor”. Uma das professoras que participou desta pesquisa é autora de materiais didáticos e diz ver a dificuldade que os professores das escolas públicas têm para pronunciar o vocabulário básico contido em seus livros. Segundo ela, além da falta de conhecimentos, outros problemas são: falta de incentivo e motivação; falta de contato com outros professores de inglês; falta de recursos e falta de materiais específicos de pronúncia para os professores, pois os livros disponíveis focam nos alunos.

\section{Resultados do questionário aplicado ao grupo comparativo}

Para proporcionar uma análise mais ampla e comparada do grupo de professores de inglês que lecionam em escolas públicas, o mesmo questionário foi aplicado a um grupo de sete professores de inglês que trabalham em escolas ou cursos particulares e quatro professoras que lecionam em universidades federais. Neste artigo, serão analisadas as mesmas perguntas que do grupo de professores de escolas da rede pública, focalizando na importância da pronúncia e no papel da mesma na formação desses professores. 
Analisando a pergunta 2 do questionário, que pede para que os participantes numerem a importância das habilidades, percebe-se que a posição ocupada pela pronúncia em relação a outras habilidades é diversificada. Dos sete professores de escolas particulares, um colocou a pronúncia na primeira posição, três a consideram terceira colocada, um marcou a quarta posição, um assinalou a quinta e outro marcou a sexta posição. No caso das quatro professoras universitárias, o resultado também foi variado, com quatro numerações diferentes: segunda, terceira, quinta e sexta.

Ao responder a questão 8, que pergunta sobre a importância do ensino da pronúncia, todos os professores de escolas particulares consideraram o ensino de pronúncia importante, pois a pronúncia é um dos fatores que “formam uma língua ou identidade linguística”, proporciona um “discurso mais claro” e “melhora a comunicação”. Quanto às professoras universitárias, três professoras consideram importante o ensino da pronúncia por fornecer instrumentos que possibilitam um estudo autodidático e independente, pela possibilidade de "gerar falha na comunicação" e pelo fato de o aluno precisar ter "a consciência de suas dificuldades e tentar sempre melhorar a sua produção”. Apenas uma professora universitária respondeu “talvez”, por ser importante “se necessário e de interesse para os alunos”.

Em relação à pergunta 11, tanto os professores das escolas particulares como os universitários consideram sua pronúncia de grande importância na aprendizagem de seus alunos, que os têm como referencial e modelo. A pronúncia do professor seria parte do "input que os alunos recebem” e é "importante que o professor queira sempre aperfeiçoar sua pronúncia para fornecer ao seu aluno input de qualidade”. Ainda, como todo professor é tido como modelo, “o professor não precisa ser o modelo da perfeição, mas ao menos executar o que ensina”.

A pergunta 4, que indaga se os professores já cursaram alguma matéria específica de pronúncia ou fonologia, obteve todas as respostas afirmativas para os professores de escolas ou cursos particulares e duas positivas para as professoras universitárias. Esse resultado é, de certa forma, surpreendente se comparado ao resultado dos professores de escolas públicas. Pode-se tentar explicá-lo pelo fato de serem professores que cursaram a graduação mais recentemente ou que cursaram pós-graduação. A maioria dos participantes falou que a experiência foi muito interessante e alguns relataram que, apesar de produtiva, foi insuficiente.

A pergunta 5, que questiona se os professores consideram o ensino de pronúncia que tiveram até hoje suficiente, obteve apenas duas respostas afirmativas: uma de um professor de uma escola particular e outra de uma professora universitária. Se relacionada com a resposta 
anterior, percebe-se que apesar da maioria destes participantes ter cursado uma matéria específica de pronúncia, ainda assim o ensino foi insuficiente. Para muitos, a pronúncia não era ensinada de forma sistemática, mas "apenas corrigida pelo professor em caso de erro cometido pelo aluno” e pontos específicos da pronúncia não eram abordados. Poderia, portanto, ter uma abordagem "mais profunda para um melhor aproveitamento e melhoramento dos conhecimentos”. Uma professora universitária que considerou o ensino suficiente diz que hoje com mais maturidade profissional, entende que não vai ser uma falante nativa de inglês, mas sim uma professora, que deve ter noções teóricas, mas não necessita saber na prática todos os conceitos vistos na aula de pronúncia.

A questão 6, que pergunta se os professores possuem dificuldade com a pronúncia da língua inglesa, obteve apenas uma resposta negativa por parte dos professores das escolas particulares, expondo o quanto esse aspecto da língua ainda é complicado para os professores, mas mostrando também que eles têm consciência de suas dificuldades. De forma geral, relataram dificuldades com as vogais do inglês, com a entonação e o acento e com a pronúncia de palavras desconhecidas.

Todas as respostas da questão 12, que perguntava se os participantes acreditavam que o conhecimento de noções teóricas da fonologia da língua inglesa era importante na sua formação de professor, foram afirmativas, tanto dos professores das escolas particulares como das professoras universitárias. Este conhecimento ajudaria a "identificar as dificuldades dos alunos na fala e encontrar uma maneira de lidar com isso”, “entender as razões pelas quais os alunos brasileiros cometem determinados erros” e ajudaria no desenvolvimento profissional do professor, auxiliando no processo de ensino-aprendizagem.

\section{Considerações Finais}

Como visto neste estudo preliminar, a maioria dos professores pesquisados considera a pronúncia importante em sua formação, apesar de não exercer um papel essencial. Os professores também demonstraram uma percepção clara da influência de sua pronúncia na de seus alunos e do quanto é importante que eles tenham uma pronúncia correta e conhecimentos teóricos que os ajudem na identificação dos problemas de seus alunos.

Os professores da rede pública que participaram desta pesquisa parecem ter tido menos chances de praticar e “aprender” pronúncia na sua formação, pois apenas dois relataram ter cursado alguma matéria específica nesta área. Como já mencionado, isso pode 
ser devido à época das graduações e ao fato de que alguns dos professores do grupo comparativo realizaram algum tipo de pós-graduação. Entretanto, mesmo com a oportunidade de realizar um estudo mais aprofundado da língua inglesa, estes professores também demonstraram uma contínua dificuldade com a pronúncia.

Um ponto positivo é que, de forma geral, os professores demonstraram interesse em aumentar seus conhecimentos de fonologia e melhorar suas pronúncias. Segundo uma professora que participou deste estudo, mais aulas de Fonologia devem ser inseridas nos cursos de graduação. É muito pouco o que os cursos oferecem nesta área e, se o professor deseja se aprimorar na língua, deve fazê-lo em cursos especializados ou em uma pósgraduação. Como sugerido por Delatorre (2007), é necessário que os cursos de Letras e o mercado de trabalho deem oportunidades para que os professores melhorem seus conhecimentos em todos os aspectos da língua que ensinam, incluindo a pronúncia, tão frequentemente negligenciada, mas essencial na formação desses profissionais.

\section{Referências}

BAPTISTA, B. O. A pesquisa na interfonologia e o ensino da pronúncia: Procurando a interface. In: FORTKAMP, M. B. M.; TOMITCH, L. M. B. (Eds.). Aspectos da lingüística aplicada: estudos em homenagem ao Professor Hilário Inácio Bohn. Florianópolis: Insular, 2000 .

BRAWERMAN, A. Uma análise de erros de estudantes brasileiros de inglês na acentuação de palavras com sufixos. Dissertação (Mestrado) - Universidade Federal do Paraná, Curitiba, 2006.

BRAWERMAN-ALBINI, A. O papel da percepção na melhora da pronúncia de falantes nãonativos. Eletras, v. 19, n. 19, 2009.

BRAWERMAN-ALBINI, A.; KLUGE, D.C. O desafio da pronúncia na formação de professores de inglês. In: ENCONTRO DO CELSUL- CIRCULO DE ESTUDOS LINGUÍSTICOS DO SUL, 9, 2010, Palhoça, SC. Anais... Palhoça: Universidade do Sul de Santa Catarina, 2010.

CRUZ, N. C. Crenças de graduandos de inglês língua estrangeira sobre a própria pronúncia. In: ABRAHÃO, M. H. V.; GIL, G. RAUBER, A. S. (Orgs.). CONGRESSO LATINOAMERICANO SOBRE FORMAÇÃO DE PROFESSORES DE LÍNGUAS, 1, 2007, Florianópolis, SC. Anais... Florianópolis : Universidade Federal de Santa Catarina, 2007.

DELATORRE, F. EFL teacher's education and the importance devoted to pronunciation in Brazil. In: ABRAHÃO, M. H. V.; GIL, G. RAUBER, A. S. (Orgs.). CONGRESSO LATINO- 
AMERICANO SOBRE FORMAÇÃO DE PROFESSORES DE LÍNGUAS, 1, 2007, Florianópolis, SC. Anais... Florianópolis : Universidade Federal de Santa Catarina, 2007..

HOLDEN, S.; ROGERS, M. O Ensino da Língua Inglesa. São Paulo: SBS, 2002.

JENKINS, J. Phonology of English as an international language: new models, new norms, new goals. Oxford: Oxford University Press, 2000.

KOERICH, R. D. Ensinar Pronúncia? In: COSTA, M. J. D. et al... (orgs.). Línguas: ensino e ações. Florianópolis: UFSC/NUSPPLE, 2002.

MOREIRA, M. A. R. The use of the mother tongue in the foreign language classroom of the Great Florianópolis (SC) region: A study of state school teachers' perceptions. Dissertação (Mestrado) - Universidade Federal de Santa Catarina, Florianópolis, 2001.

WATKINS, M. A.; BRAWERMAN-ALBINI, A.; BERTOCHI, M.. Suffering from Stress: Two English Stress Patterns that Give Brazilians a Hard Time. In: RAUBER, A. S. et al. (orgs.). The acquisition of second language speech: studies in honor of professor Barbara $\mathrm{O}$. Baptista. Florianópolis: Insular, 2010.

ANEXO

\section{QUESTIONÁRIO}

1. Identificação:

Email:

Onde você ensina inglês?

Há quanto tempo?

Você é formado em Letras?

Como você aprendeu a língua inglesa?

2. Numere as habilidades abaixo da mais importante (1) para a menos importante (6) na aprendizagem da língua inglesa, na sua opinião:
( ) leitura
( ) escrita
( ) fala
( ) compreensão oral
( ) pronúncia
( ) conhecimento de gramática

3. Você acredita que uma pronúncia deficiente possa prejudicar a comunicação? Como?

4. Você cursou alguma matéria específica de pronúncia ou fonologia da língua inglesa no seu curso de graduação? Caso a resposta seja afirmativa, o que achou da experiência? Se negativa, esse tipo de matéria costumava ser ofertada? Caso tenha sido ofertada, por que não cursou? 
5. Como você classifica o ensino de pronúncia que teve durante sua formação? Foi suficiente ou seus professores focaram pouco nesse assunto?

6. Você tem dificuldades com a pronúncia da língua inglesa? Quais suas maiores dificuldades?

7. Quais os problemas de pronúncia que você mais identifica nos seus alunos?

8. Você acredita que o ensino de pronúncia seja importante? Por quê?

9. Você ensina pronúncia na sala de aula? Com que frequência? De que forma?

10. Você se sente à vontade para ensinar pronúncia? Por quê?

11. Como professor de inglês, como você destacaria a importância da SUA pronúncia na aprendizagem de seus alunos?

12. Você acredita que o conhecimento de noções teóricas da fonologia da língua inglesa seja importante na sua formação de professor? Por quê? 